\title{
28 Research Square \\ Is Pollution Haven Hypothesis Valid in Turkey? New Evidence From Fourier Approach
}

\section{Nilgun Cil ( $\nabla$ nilgun.cil@istanbul.edu.tr)}

Istanbul University: Istanbul Universitesi https://orcid.org/0000-0003-4732-227X

\section{Research Article}

Keywords: Pollution Haven Hypothesis, CO2 emissions, EKC hypothesis, Foreign Direct Investment, Energy consumption, Fourier approach, Turkey

Posted Date: February 22nd, 2022

DOI: https://doi.org/10.21203/rs.3.rs-1281011/v1

License: (c) (i) This work is licensed under a Creative Commons Attribution 4.0 International License. Read Full License 
Is Pollution Haven hypothesis valid in Turkey? New evidence from Fourier approach

\section{Nilgun Cil ${ }^{1}$}

\author{
${ }^{1}$ Faculty of Economics, Department of Econometrics, Istanbul University, Istanbul, Turkey \\ (Corresponding Author) \\ E-mail: nilgun.cil@istanbul.edu.tr
}

Address: Siddık Sami Onar Street. Istanbul University Central Campus Faculty of Economics, Department of Econometrics Beyazit/Fatih/ Istanbul Postal Code: 34452

\section{Abstract} region of the world since the late 1980s, have been the subject of long and contentious debates about the costs and benefits for the host country, especially for developing countries. In this context, this study investigates the impact of FDI on environmental quality in the case of Turkey which is developing country, for the period 1970-2016. For this purpose, unlike existing studies, we use Fourier approach that is capable of capturing gradual or smooth shifts, in our empirical analysis. The findings of empirical analysis indicate that FDI has a positive impact on environmental degradation, so Pollution Haven Hypothesis (PHH) is valid for Turkey. Our results reveal the inverted U-shape or the environmental Kuznets Curve (EKC) relationship between economic growth and $\mathrm{CO}_{2}$ emissions. We also find that energy consumption significantly increases environmental degradation in Turkey.

Keywords: Pollution Haven Hypothesis, $\mathrm{CO}_{2}$ emissions, EKC hypothesis, Foreign Direct Investment, Energy consumption, Fourier approach, Turkey

\section{Introduction}

In recent decades, the economic, social and the environmental impacts of globalization have been the most discussed topics especially in terms of developing countries. Foreign direct investment (FDI) that is one of the processes of globalization is an important source in financing the current account deficit for especially developing countries besides it is important in terms of supporting the use of new technology instead of old technology in production, thus increasing productivity and supporting companies to open up to new foreign markets. Foreign direct 
investments also have the potential to affect the host country's other macroeconomic variables such as income, investment and employment. In the point of view developing countries, although it seems that enhancing capital inflows by encouraging foreign direct investment will ensure economic growth and sustainable development, environmentalists and policymakers debate that the rapid economic development also brings conspicuous environmental problems such as, the global warming associated with increasing greenhouse gas emissions, and hence climate change.

On the other hand, there is consensus in the area of energy economics that energy demand as the input of the production process is the main driver of environmental degradation (see also,Charfeddine, 2017; Pao \& Tsai, 2010; Soytas \& Sari, 2003; Soytas et al., 2007; Ang, 2007; Apergis \& Payne, 2009; Arouri et al., 2012).Considering that, especially in developing countries, use of fossil fuel-based energy consumption has an important share in total energy consumption, environmental effects of foreign direct investments which increasing economic activities is becoming more important for these countries. Grossman \& Krueger (1991) state that growing foreign direct investments can influence environmental pollution as a result of increasing energy consumption, and is named this indirect effect of foreign direct investments on pollution of the host country as the scale effect. In this context, foreign direct investments accelerate industrial activities and hence economic growth with the effect of scale in short-term. Since energy-intensive economic activities and infrastructural development lead to more energy use, this situation significantly contribute to the increase in the pollution level of the host country in long term.

Theoretically the relationship between economic growth and environmental degradation has been explained by Environmental Kuznets Curve (EKC) hypothesis. In the context of globalization, however, there are two different views regarding the possible impacts of foreign direct investment especially on the environment of host country. According to the EKC hypothesis that was first proposed and tested in their seminal paper of Grossman \& Krueger, (1991), during the early stages of economic growth, when the per capita income grows, the environmental pollution increases up to a certain point. After it reaches a threshold value, the environmental pollution decreases. In other words, the EKC hypothesis postulates an inverted U-shaped relationship between the level of environmental degradation and income growth. Following Grossman \& Krueger (1991, 1995), the validity of EKC hypothesis has been tested by numerous studies for countries, regions and country groups using different econometric methods but there has been no consensus among researchers yet. On the one hand, Roca et al. (2001), Day and Grafton (2003), Pao and Tsai (2011a), Pao and Tsai (2011b), Holtz-Eakin and 
Selden (1995), Shafik (1994), Panayotou (1993), Furuoka (2015) argue that economic development does not have adverse effects on the environment and thus the validty of EKC hypothesis is not proved. On the other hand, Ang (2007), Shahbaz et al. (2014), Pao and Tsai (2010), Apergis and Payne (2009), Shahbaz et al. (2012), Halicioglu (2009), Wang et al. (2017) claim that economic growth causes an increase in $\mathrm{CO}_{2}$ emissions and therefore environmental pollution.

Foreign direct investment and the environmental quality nexus is described with Pollution Haven Hypothesis (PHH) and Pollution Halo Hypothesis (PHL). According to PHH Walter \& Ugelow (1979), multinational enterprises in developed countries tend to move their pollution intensive industries to developing countries where environmental regulations are less stringent, because of high implementation cost and carbon tax. Thus, pollution-intensive industries that has transferred with FDI significantly rise carbon emissions and so environmental pollution in host countries through usage of old and non environmental friendly technologies, see also, Gray (2002), Perkins and Neumayer (2009), Talukdar and Meisner (2001). Contrary to the PHH, Pollution Halo Hypothesis states that FDI could positively affect the environment quality and reduce pollution in the host country via the transfer of advanced technologies production and better management practices from developed to developing countries according to Zarsky (1999). Cole (2004) states that due to a change in production methods (technical effect), the possible effects of foreign direct investments at the level of pollution would be in a decreasing direction. Kearsley and Riddel (2010) also stated that the liberalization in the context of FDI inflows may act to reduce $\mathrm{CO}_{2}$ emissions, due to increased competitive pressure encourages countries by using more efficient their resources. As a result, the effect of the FDI inflows on $\mathrm{CO}_{2}$ emissisons and therefore on the environment (i.e the validity of PHH or PHL) would depend on the nature of technologies (dirty or clean) used of foreign direct investments, which transfering into host country (Sun et al. 2017, Opoku et al. 2021).

In particular, since Taylor (2005) stated that the environmental effects of trade flows and FDI have been at the center of the debate, researchers have devoted extensive effort to investigate whether the FDI inflows causes environmental degradation in the host country or not. In these studies, FDI and/or trade flows are generally considered as an additional variable to the model testing the validity of the EKC hypothesis. Also, when EKC hypothesis is being tested, if the PHH is valid, but international trade and its potential effect on the environmental degradation is ignored, both the estimates of parameters in the model and so estimate of the EKC's turning point will be biased Cole (2004); Kearsley and Riddel (2010). Despite there 
103 have been numerous studies using different econometric methods, examining the relationship 104 between foreign direct investment and environmental degradation, empirical evidences of these studies are mixed and there have been presently not a consensus with regarding the relationship between them. Some studies found that FDI inflows cause environmental degradation, i.e. PHH is valid, (e.g. Cole \& Elliott, 2005; Pao and Tsai, 2011a; Shahbaz et al. 2015; Omri et al. 2014; Tang and Tan, 2015; Al-mulali, 2012; Al-Mulali and Ozturk, 2015; Shahbaz et al. 2018; Wang et al. 2018; Sun et al. 2017; De Camargo Fiorini et al. 2019; Acharyya, 2009), while some other studies concluded that FDI inflows reduce pollution by transferring more environmental friendly technologies from developed countries to host country, i.e. PHL is valid. (e.g. Gray 2002, Tang and Tan, 2015, Kirkulak et al. 2011, Atici 2012, Lee 2013, Zhang and Zhou 2016). the possible impacts of foreign direct investment inflows on environmental quality in Turkey, focusing on subject PHH in context to EKC. In Turkey, especially with the structural transformation process experienced in 1980, a policy of transition from import substitution strategy to an export-oriented economy was followed. Within the framework of this policy followed, to finance the current account deficit, increase capital accumulation and economic growth, FDI has encouraged by economic reforms removing the obstacles to international capital movements. However, FDI inflows to Turkey were quite low from 1980 until the early 2000s. FDI inflows reached its peak in 2007 to 22.047 billion (in current USA) increasing from 982 million in 2001, with the implementation of the strong economy program to overcome the 2001 economic crisis. Due to 2007 financial crisis in the world and Turkey, however, international capital flows were significantly reduced, and FDI inflows in 2009 were 6.333 billion, being below the level of the year 2005. Although FDI inflows has increased since 2009, it has displayed a fluctuating movement until today.

As a developing country, Turkey has been a remarkable country with dramatically increasing greenhouse gas emissions significantly since the1980s. The reason of this is the increase in the demand for energy as a result of high economic growth in recent years. As in most countries, the energy demand in Turkey is largely covered by the fossil fuel causing rising greenhouse gas emissions and environmental degradation. According to the Turkish Statistical Institute' (TUIK) data 2016 year, for Turkey, $\mathrm{CO}_{2}$ emissions has the share of eighty one percent in total greenhouse gas emissions and hence it is the major determinant of greenhouse gas emissions causing pollution. Turkey also exhibits a rising trend in the world $\mathrm{CO}_{2}$ emissions rankings. While rank of Turkey was 35th and 22th in 1980 and 2000 respectively, in 2019, with 
$1361.1 \%$ share of the world's total $\mathrm{CO}_{2}$ emissions was 16 th according to the World rankings 137 (Global Carbon Atlas).

138 Briefly, Turkey has been made an increase in FDI inflows, gross domestic product 139 (GDP), energy consumption and $\mathrm{CO}_{2}$ emissions last four decades. Therefore, exploring the 140 relationship between these variables could be of interest in the context of Turkey. However, 141 there are limited empirical studies about investigating relationship between FDI and 142 environmental degradation focusing particularly on the Turkey.

143 In one of these studies, Seker et al. (2015) investigated the impact of FDI on $\mathrm{CO}_{2}$ 144 emissions by employing the ARDL bounds test and Hatemi-J cointegration test taking structural 145 breaks into consideration for Turkey over the period 1974-2010. It was found that the effect of 146 FDI on $\mathrm{CO}_{2}$ emissions is positive but relatively small and the EKC hypothesis is valid. 147 Similarly, Gökmenoğlu and Taspinar (2016) also examined the impact of FDI, economic 148 growth and energy consumption on $\mathrm{CO}_{2}$ emissions with the framework EKC employing the 149 ARDL bounds test and found evidences in favor of both the PHH and EKC hypotheses in the 150 Turkey. In another study Koçak and Şarkgüneşi (2018) concluded that the potential impact of 151 FDI on $\mathrm{CO}_{2}$ emissions is positive in Turkey and $\mathrm{PHH}$ is valid. The findings also provide 152 evidence for the existence of the EKC hypothesis. The empirical findings of the study by Bulut 153 et al. (2021), using unit root and cointegration methods based on nonlinear smooth transition 154 models, show that both EKC hypothesis and PHH are valid for Turkey. On the other hand, Haug 155 and Ucal (2019) examined the effects of foreign trade and FDI on $\mathrm{CO}_{2}$ emissions by using linear 156 and nonlinear ARDL models. They showed that, in the long run, FDI is a not leading to 157 increases in $\mathrm{CO}_{2}$ emissions per capita, unlike the findings of other studies. More spesificially, 158 the empirical findings of PHH for Turkey is mixed. More spesificially, it has been observed 159 that the empirical findings of PHH for Turkey is mixed.

160 The main difference of this research from previous studies investigating the possible 161 effects of foreign direct investment inflows, economic growth and energy consumption on $\mathrm{CO}_{2}$ 162 emissions is the usage of the recently developed Fourier approximation to determine the stationarity properties of the variables and to analyze the relationship between them. Enders and Lee (2012a) stated that the Fourier approximation determine the probability of gradual/smooth structural changes, sharp breaks, and other nonlinear trends by using the

166 frequency component of the Fourier function. Several authors (Becker et al. 2004, 2006; 167 Enders and Lee 2012a, 2012b) show that a Fourier approximation often capture the behavior of 168 an unknown function even if the function itself is not periodic. They also ensure that the tests 169 have good size and power properties irrespective of the time or shape of the break, by reducing 
170

171

172

173

174

175

176

177

178

179

180

181

182

183

184

185

186

the number of estimated parameters especially in small sample. To the best our knowledge, this study is the first to use the Fourier approach to investigate the stochastic properties of variables, the existence of cointegrating and causality (FDI, economic growth, energy consumption and $\mathrm{CO}_{2}$ emissions) in the model to testing validty of $\mathrm{PHH}$. This study contributes to the literature with this aspect.

The rest of the paper is organized as follows: Section 2 describes the data, data source and the model. Section 3 introduces framework of econometric methods used for empirical analysis. Section 4 provides the empirical results, and Section 5 concludes with a discussion of the findings.

\section{Data description and model specification}

The goal of this study is to investigate the validity of the PHH for Turkey in within the context of the EKC hypothesis. In line with this purpose, this section presents the variables employed and their data sources, as well as the model specification. All data used in this study are annual observations and covering the period from 1970 to 2016. The brief description of the variables used in analysis is presented in Table 1.

Table 1: Variables, explanation, unit of variables and data source.

\begin{tabular}{|c|c|c|c|}
\hline Variable & Description & Unit & Data Source \\
\hline $\mathrm{CO}_{2}$ & $\mathrm{CO}_{2}$ emissions per capita & $\begin{array}{l}\text { Metrics tons per } \\
\text { capita }\end{array}$ & World Development Indicators \\
\hline$G D P$ & $\begin{array}{c}\text { Per capita real Gross Domestic } \\
\text { Product }\end{array}$ & $\begin{array}{l}\text { Constant } 2010 \\
\text { USA dolar }\end{array}$ & World Development Indicators \\
\hline$F D I$ & $\begin{array}{c}\text { Per capita real Foreign Direct } \\
\text { Investment }\end{array}$ & $\begin{array}{l}\text { Constant } 2010 \\
\text { USA dolar }\end{array}$ & World Development Indicators \\
\hline$E C$ & Per capita energy consumption & $\begin{array}{l}\text { Kilogram of oil } \\
\text { equivalent per } \\
\text { capita }\end{array}$ & $\begin{array}{c}\text { British Petrol Statistical } \\
\text { Review }\end{array}$ \\
\hline
\end{tabular}

187

188

189

190

191

192

193

194

195

In this study, the model is constructed as following:

$$
C \mathrm{O}_{2}=f(G D P, F D I, E C)
$$

where, $\mathrm{CO}_{2}$ is per capita carbon dioxide emissions as proxy environmental degradation, GDP is the per capita real GDP as a measure of economic development, FDI is per capita real foreign direct investment and EC is the per capita energy consumption. The specification of model investigating the possible relationship between environmental degradation and economic indicators is determined by context of both EKC hypothesis and PHH. It is built on the existing 
196 literature (see also, Tang and Tan 2015, Halicioglu 2009, Ang 2007, Merican et al. 2007) and, 197 is as the following:

$198 \ln C O_{2 t}=\beta_{0}+\beta_{1} \ln G D P_{t}+\beta_{2} \ln G D P_{t}^{2}+\beta_{3} \ln F D I_{t}+\beta_{4} \ln E C_{t}+\varepsilon_{t}$

199 where $t=1, \ldots, T$ represents the time period and $\varepsilon_{t}$ is white noise stochastic disturbance term, is 200 assumed to be normally distributed. Considering the possibility of different variance in data, all variables are converted into natural logs, thus the first difference of the variables can be 202 interpreted as the growth rate. Also, the coefficients $\left(\beta_{1}, \beta_{2}, \beta_{3}\right.$ and $\left.\beta_{4}\right)$ give the long-term 203 elasticity of the per capita $\mathrm{CO}_{2}$ emission according to the respective variables. The econometric model includes both the level and square of GDP to test EKC hypothesis. While the aim of this study provides testing PHH, FDI is also included. There are some conditions to determine the validity of the EKC hypothesis and PHH. Firstly, there must be a cointegration relationship among the variables in the Equation 2. Under the EKC hypothesis, the coefficient of $\beta_{1}$ and $\beta_{2}$ should be positive and negative respectively. And also they must be statistically significant. Thus, the relationship between economic growth and environmental degradation is "an inverted U-shaped", showing the EKC hypothesis is valid in Turkey; otherwise, EKC hypothesis would be failed to verify. In the case of EKC hypothesis is valid, the turning point of curve is calculated

212 by $\left(-\beta_{1} / 2 \beta_{2}\right)$. For logarithmic equations, this point can be computed by calculation $\exp ($ $213-\beta_{1} / 2 \beta_{2}$ ) as suggested by Dinda (2004) and it yields the monetary value. If coefficient $\beta_{2}$ is 214 found to be statistically insignificant, Halicioglu (2009) states that there is a monotonically 215 linear relationship between per capita of $\mathrm{CO}_{2}$ emissions and GDP. The expected sign of $\beta_{3}$ 216 depends on whether the technology used by FDI is dirty or not. If $\beta_{3}$ has a positive sign and is

217 found as statistically significant, we can conclude that there is an evidence for PHH. If $\beta_{3}$ has 218 a negative sign and is found as statistically significant, we can conclude that there is an evidence 219 for PHL. Besides, as stated above, due to a widespread opinion from studies conducted in recent 220 years that energy consumption increases environmental degradation shows that the sign of $\beta_{4}$ 221 is expected to be positive.

Table 2. Descriptive statistics of variables (before taking logarithm)

\begin{tabular}{|c|c|c|c|c|}
\hline & CO2 & GDP & FDI & EC \\
\hline Mean & $2.69 \mathrm{E}-06$ & 7697.085 & 61.97928 & 41.14209 \\
\hline Maximum & $4.50 \mathrm{E}-06$ & 14153.46 & 329.2681 & 75.29632 \\
\hline
\end{tabular}




\begin{tabular}{|c|c|c|c|c|}
\hline Minimum & $1.13 \mathrm{E}-06$ & 4220.885 & 0.759396 & 15.07769 \\
\hline Std. Dev. & $9.65 \mathrm{E}-07$ & 2764.230 & 91.55586 & 16.95330 \\
\hline Jarque-Bera & 2.741603 & 5.359120 & 23.60565 & 2.751839 \\
\hline Probability & 0.253903 & 0.068593 & 0.000007 & 0.252607 \\
\hline
\end{tabular}

A general descriptive statistics for the actual values of variables used for the study is presented in Table 2. The Jargue-Bera statistic shows that real GDP per capita and FDI per capita do not follow normal distribution while $\mathrm{CO}_{2}$ per capita and $\mathrm{EC}$ per capita follow normal distribution. But, in our econometric analysis, logarithmic forms of all variables are used and they follow normal distribution. The GDP seems to have greatest variation (defined by the standard deviation) among the variables.

\section{Empirical methodology}

In this section, we briefly present the unit root/stationarity tests, the cointegration tests and Toda-Yamamoto causality test that are based on the Fourier approximation, used in our analysis.

\subsection{Fourier stationarity test}

Becker et al. (2006) developed the Fourier stationarity test by extending the traditional stationarity test of Kwiatkowski et al. (1992) with a Fourier function that allows the deterministic term in the regression to be a time-dependent function. In this test known as Fourier KPSS (FKPSS), the unknown forms and /or number of structural breaks can be captured by using a selected frequency component of a Fourier function.

Becker et al. (2006) consider the following data generating process (DGP):

$y_{t}=\alpha+\beta t+\gamma_{1} \sin (2 \pi k t / T)+\gamma_{2} \cos (2 \pi k t / T)+r_{t}+\varepsilon_{t}$

where the $r_{t}$ process is defined as:

$r_{t}=r_{t-1}+u_{t}$

where $\varepsilon_{t}$ are the stationary errors and $u_{t}$ are the independent and identically distributed (i.i.d) with variance $\sigma_{u}^{2} \cdot[\sin (2 \pi k t / T), \cos (2 \pi k t / T)]$ captures structural change in the deterministic term, where $k$ is the frequency and $T$ the sample size. The rationale for selecting $[\sin (2 \pi k t / T), \cos (2 \pi k t / T)]^{\prime} \quad$ is $\quad$ based $\quad$ on $\quad$ the fact 
that a Fourier expansion is capable of approximating absolutely integrable 251 functions to any desired degree of accuracy. $\gamma=\left[\gamma_{1}, \gamma_{2}\right]^{\prime}$ measures the amplitude and displacement of the frequency component. If the null hypothesis $\gamma_{1}=\gamma_{2}=0$ is rejected, the series must have a nonlinear component.

256 the residuals from the following equations:

258 or

$y_{t}=\alpha+\beta t+\gamma_{1} \sin (2 \pi k t / T)+\gamma_{2} \cos (2 \pi k t / T)+e_{t}$

While one can test the null of level stationarity using Eq. 5, can test the null of trend stationarity employing Eq.6. To determine the optimal frequency ( $k$ ) in Eq. (5) or Eq. (6), one can select the $k$ which minimizes of the sum of squared residuals. For testing the null hypothesis of stationarity (i.e $\sigma_{u}^{2}=0$ ), the test statistic ( $\left.\tau_{K P S S}\right)$ is given as below;

$\tau_{\mu}(k)$ or $\tau_{T}(k)=\frac{1}{T^{2}} \frac{\sum_{t=1}^{T} \oiint_{t} /(k)^{2}}{\delta / \%}$

267 where $S_{t}^{\& / 0}(k)=\sum_{j=1}^{t} \mathcal{E}_{j}$ and $\mathscr{E j}$ are the OLS residuals from the regression in Eq. (5) for $\tau_{\mu}(k)$ or Eq.(6) for $\tau_{T}(k)$. As in the KPSS and following the PP-type approach, Becker et al. (2006) suggest a nonparametric estimate of Kwiatkowski et al. (1992) the long-run variance ( $\& \overbrace{}^{\prime})$ in the Eq (7) can be obtained by choosing a truncation lag parametre $l$ and a set of weights $w_{j}$, $j=1, \mathrm{~K}, l$ :

$8 \%=9 \%+2 \sum w_{j} \% \%$

where $\% \%$ is the $j$ th sample autocovariance of the residuals $e_{t}^{2}$ from Eq (5) or Eq (6).

\subsection{Flexible Fourier unit root test}

Another test that investigates the stochastic properties of a series using the Fourier function is the Fourier DF-type unit root test that is so-called the Flexible Fourier ADF (FF- 
ADF) that proposed by Enders and Lee (2012b). This test is also useful in existence of unknown multiple breaks in a nonlinear fashion.

The Dickey-Fuller type unit root test in which deterministic terms $\alpha(t)$ is a time dependent function is, as following.

$y_{t}=\alpha(t)+\rho y_{t-1}+\gamma t+\varepsilon_{t}$

where $\varepsilon_{t}$ is a stationary disturbance with variance $\sigma_{\varepsilon}^{2}$ and $\alpha(t)$ is a deterministic function of t. DF unit root test is based on testing null hypothesis of a unit root (i.e., $\rho=1$ ). However, if the form of $\alpha(t)$ is unknown, the application of any unit root test for $\rho=1$ is problematic. In case the functional form the $\alpha(t)$ is unknown, Enders and Lee (2012b) propose to use the Fourier expansion as a proxy for the unknown functional form of $\alpha(t)$,

$\alpha(t)=\alpha_{0}+\sum_{k=1}^{n} \alpha_{k} \sin (2 \pi k t / T)+\sum_{k=1}^{n} \beta_{k} \cos (2 \pi k t / T) \quad, \quad n \leq T / 2$

where $n$ is the number of frequencies included in the approximation, $k$ is specific frequency, $t$ is trend term, and $T$ is the number of observations. If the null hypothesis $\alpha_{1}=\beta_{1}=\alpha_{2}=\beta_{2}=\mathrm{L}=\alpha_{n}=\beta_{n}=0$ cannot be rejected, the process is linear and the traditional unit root test methodologies are appropriate. However, if there is a break or a nonlinear trend, at least one Fourier frequency must be present in the data generating process (Enders and Lee 2012b). In the single frequency $(k)$ case, Fourier DF-type unit root test is based on the estimation of the regression model in below.

$\Delta y_{t}=\rho y_{t-1}+c_{1}+c_{2} t+c_{3} \sin (2 \pi k t / T)+c_{4} \cos (2 \pi k t / T)+e_{t}$

$\tau_{D F}$ denotes the $t$ - statistic for the null hypothesis $\rho=0$ in Eq. (10). Optimal frequency $(\hat{k})$ is obtained via the minimization of the sum of squared residuals in the interval $1 \leq k \leq 5$. The critical values for testing the null hypothesis of a unit root depend on the asymptotic properties of Fourier unit root test based on DF the same as that the LM version of Fourier unit root test. Enders and Lee (2012b) state that the critical values for the null hypothesis of a unit root depend only on the frequency $k$ and the sample size $T$, and do not depend on the coefficients of the Fourier terms or other deterministic terms. Critical values of $\tau_{D F}$ obtain with Monte Carlo simulations are reported in Enders and Lee (2012b).

Enders and Lee (2012b) also state that the DF version tests with level shifts when linear trend is absent, are robust in the presence of a large initial value and can be more powerful than 
both LM version Enders and Lee (2012a) and the DF-GLS version (Rodrigues and Robert

309 Taylor, 2012) tests.

\subsection{Fourier ADL cointegration test}

In the case of structural changes, the results of cointegration test like unit root tests also may be biased. Since cointegration tests that allow structural changes through dummy variables only consider sharp breaks, new cointegration tests that consider multiple smooth changes via a Fourier functions have been proposed recently. One of them, the cointegration test is that are suggested by Banerjee et al. (2017). This test is based the Autoregressive Distributive Lag (ADL) model which includes a Fourier function in the deterministic term to allow for unknown form of nonlinear breaks Banerjee et al. (2017) defined as in Enders and Lee (2012a), $d(t)$ is the deterministic term that includes a nonlinear function of time, and is as follows:

$d(t)=\gamma_{0}+\sum_{i=1}^{q} \gamma_{1, k} \sin (2 \pi k t / T)+\sum_{i=1}^{q} \gamma_{2, k} \cos (2 \pi k t / T) \quad q \leq T / 2$

where $\gamma_{0}$ denotes the usual deterministic term including a constant a linear trend, $k$ represents a particular single frequency, $q$ represents the number of frequencies contained in the approximation, and $T$ is the number of observations. In the absence of a nonlinear trend, i.e., $\gamma_{1, k}=\gamma_{2, k}=0$, for all $k$; Eq. (11) collapses to $\gamma_{0}$ which is usual deterministic term. In that case, conventional ADL test is applicable. If $\gamma_{1, k}=\gamma_{2, k}=0$ is rejected, Fourier ADL cointegration test is applied.

Banerjee et al. (2017) use the following conditional model to describe the Fourier ADL testing procedure:

$\Delta y_{1 t}=d(t)+\delta_{1} y_{1, t-1}+\gamma^{\prime} y_{2, t-1}+\varphi^{\prime} \Delta y_{2 t}+\varepsilon_{t}$

331 where the dependent variable $y_{1 t}$ is a univariate process and $\delta_{1}$ is a scalar. $\gamma, \varphi$ and $y_{2 t}$ are $n$ $332 \times 1$ vector of parameters and explanatory variables. Deterministic term, $d(t)$, includes a nonlinear function of time. Lags of $\Delta y_{1 t}$ and $\Delta y_{2 t}$ are allowed to control for the possible serial correlation in $\varepsilon_{t}$. The null hypothesis of no cointegration $\left(H_{0}: \delta_{1}=0\right)$ is tested against the alternative of the presence of cointegration $\left(H_{0}: \delta_{1}<0\right)$. The $t$ - statistics to test the null hypothesis $\delta_{1}=0$ in Eq. 12 is defined by: 
$t_{A D L}^{F}=\frac{\hat{\delta}_{1}}{\operatorname{Se}\left(\hat{\delta}_{1}\right)}$

338 where $\hat{\delta}_{1}$ is the OLS estimator of $\delta_{1}$ in Eq (12) and $\operatorname{Se}\left(\hat{\delta}_{1}\right)$ is a standard error of $\hat{\delta}_{1}$. The

339 critical values are reported in Banerjee et al. (2017).

\subsection{Fourier Shin cointegration test}

In order to investigate the long-term relationship among the variables, Tsong et al. (2016) propose another cointegration test in which the Fourier approach using to accommodate possible structural breaks in unknown forms and numbers, as Banerjee et al. (2017).

Test is based on the following cointegration regression:

$y_{t}=d_{t}+x_{t}^{\prime} \beta+\eta_{t}$

$$
t=1,2, \mathrm{~K}, T
$$

348 where $d_{t}$ is deterministic component, $\eta_{t}=\gamma_{t}+v_{1 t}, \gamma_{t}=\gamma_{t-1}+u_{t}$ with $\gamma_{0}=0$, with $x_{t}=x_{t-1}+v_{2 t}$

349 . Here $u_{t}$ is i.i.d process with zero mean and variance $\sigma_{u}^{2}$. There for $\gamma_{t}$ is random walk with 350 mean zero. Deterministic component $\left(d_{t}\right)$ in Eq. $(13)$ is assumed as,

$$
d_{t}=\sum_{i=0}^{m} \delta_{i} t^{i}+f_{t}
$$

353 where

$354 f_{t}=\alpha_{k} \sin \left(\frac{2 k \pi t}{T}\right)+\beta_{k} \cos \left(\frac{2 k \pi t}{T}\right)$

356 The scalar $v_{1 t}$ and $p$-vector $v_{2 t}$ are stationary, and hence, $y_{t}$ and $x_{t}$ are all I(1) process. If $357 \sigma_{u}^{2}=0, \eta_{t}=v_{1 t}$ is a stationary process, implying that $y_{t}$ and $x_{t}$ are cointegrated. The null 358 hypothesis of cointegration against the alternative of non-cointegration is, as follows

$$
H_{0}: \sigma_{u}^{2}=0 \quad \text { versus } \quad H_{1}: \sigma_{u}^{2}>0
$$

360 Under hypothesis $\left(H_{0}: \sigma_{u}^{2}=0\right)$, the model is rewritten as:

$$
y_{t}=\sum_{i=0}^{m} \delta_{i} t^{i}+\alpha_{k} \sin \left(\frac{2 k \pi t}{T}\right)+\beta_{k} \cos \left(\frac{2 k \pi t}{T}\right)+x_{t}^{\prime} \beta+v_{1 t}
$$


The Shin-type cointegration statistic $\left(C I_{f}^{m}\right)$ to test the null of cointegration with structural breaks against the alternative of non-cointegration is given by:

$364 \quad C I_{f}^{m}=T^{-2} \hat{\omega}_{1}^{-2} \sum_{t=1}^{T} S_{t}^{2}$

365 where $S_{t}=\sum_{t=1}^{T} v_{1 t}$ is the partial sum of the ordinary least squares (OLS) residuals from Eq. (16)

366 and $\hat{\omega}_{1}^{2}$ is the consistent estimator fort he long-run variance $v_{1 t}$. Asymptotic critical values for 367 the $C I_{f}^{m}$ test are tabulated in Tsong et al. (2015).

\subsection{Fourier Toda-Yamamoto causality test}

Although the Granger causality test is frequently used to draw inference concerning causality in applied economics, the literature in the last years shows that considering structural shifts plays the important role in causality analysis. In this context, Ventosa-Santaulària and Vera-Valdés (2008) demonstrate that when there is structural shifts in the data generating process but it is ignored in the estimations, the non-causality null hypothesis can be rejected even when two variables do not have a causal link. Enders and Jones (2016) also indicate ignored structural breaks in VAR result in a mis-specified model such that Granger causality tests are improperly sized, and there is a bias towards a rejection of the null hypothesis of noncausality even when the null is correct. Enders and Jones (2016) show that the flexible Fourier form has good size and power properties in testing for smooth structural change in a VAR with the Monte Carlo simulations.

Nazlioglu et al. (2016) propose a new approach by extending the Toda and Yamamoto (1995) Granger causality procedure with a Fourier approach to take into account structural breaks in causality analysis. This approach is capable of capturing gradual or smooth shifts and does not require a prior knowledge regarding the number, dates, and form of structural breaks. In order to account for structural breaks in this test the so-called fourier Toda- Yamamoto causality test, the assumption of the intercept terms are stable over time is relaxed by Nazlioglu et al. (2016) and VAR (p+d) model is defined as following

$$
y_{t}=\alpha(t)+\beta_{1} y_{t-1}+\mathrm{L}+\beta_{p+d} y_{t-(p+d)}+u_{t}
$$

where, intercept terms $\alpha(t)$ are the functions of time and denote any structural shift in $y_{t}$, and are defined as below 


$$
\alpha(t)=\alpha_{0}+\sum_{k=1}^{n} \gamma_{1 k} \sin \left(\frac{2 n k t}{T}\right)+\sum_{k=1}^{n} \gamma_{2 k} \cos \left(\frac{2 n k t}{T}\right)
$$

393 where $n$ is the number of frequencies, $k$ is the frequency, $\gamma_{1 k}$ and $\gamma_{2 k}$ measures the amplitude 394 and displacement of the frequency, respectively. By substituting Eq 19 in Eq 18, the following equation is obtained.

$$
y_{t}=\alpha_{0}+\sum_{k=1}^{n} \gamma_{1 k} \sin \left(\frac{2 n k t}{T}\right)+\sum_{k=1}^{n} \gamma_{2 k} \cos \left(\frac{2 n k t}{T}\right)+\beta_{1} y_{t-1}+\mathrm{L}+\beta_{(p+d)} y_{t-(p+d)}+u_{t}
$$

Ludlow and Enders (2000) stated that a single frequency component is enough to approximate the Fourier expansion. Thus, Eq (19) and Eq (20) can be written as, respectively

$$
\alpha(t)=\alpha_{0}+\gamma_{1 k} \sin \left(\frac{2 n k t}{T}\right)+\gamma_{2 k} \cos \left(\frac{2 n k t}{T}\right)
$$

and

$$
y_{t}=\alpha_{0}+\gamma_{1} \sin \left(\frac{2 n k t}{T}\right)+\gamma_{2} \cos \left(\frac{2 n k t}{T}\right)+\beta_{1} y_{t-1}+\mathrm{L}+\beta_{(p+d)} y_{t-(p+d)}+u_{t}
$$

In the Toda-Yamamoto framework, the null hypothesis of Granger non-causality based on zero restriction on first $p$ parameters $\left(H_{0}: \beta_{1}=\mathrm{L}=\beta_{p}\right)$ on the variable of interest. Wald statistic for the null hypothesis has the chi-square distribution with $p$ degrees of freedom. The optimal number $p$ and $\mathrm{k}$ is determined with the smallest value of an information criterion such as Akaike or Schwarz. Recent studies in the causality literature indicate that the use of bootstrap distribution is robust, because it increases the power of test statistics in small samples. So, by following the suggestion of Nazlioglu et al. (2016), we use bootstrap simulations to obtain necessary critical values.

\section{Empirical results}

Prior to estimating long-run parameters in the empirical model for investigating $\mathrm{PHH}$ hypothesis in Turkey, the stochastic properties of the variables in the model (Eq.2) is tested to avoid the possible spurious regression problem. As stated earlier, there is a growing consensus that conventional unit root tests fail to incorporate the structural breaks in the structure of the series. Perron (1989) has pointed out that the power to reject a unit root decreases if the 
stationary alternative is true when the structural break is ignored. Due to the shortcoming of conventional unit root tests when a time series contains structural breaks, Fourier stationarity /unit root tests, which can capture the probability of gradual structural changes, sharp breaks, and other nonlinear trends, are used to investigate the stationarity properties of the variables. Therefore, in our paper, we proceed to test stochastic properties of the variables by using FKPSS stationarity test and FF-ADF unit root test with a Fourier function proposed by Becker et al. (2006) and (Enders \& Lee, 2012b), respectively. Results of stationarity / unit root tests based on Fourier approximation are tabulated in Table 3.

Table 3 The Results of Fourier stationarity/unit root tests

\begin{tabular}{lcccc}
\hline Variables & FKPSS & $k^{*}$ & FF-ADF & $k^{*}$ \\
\hline \hline $\ln \mathrm{CO}_{2}$ & $0.406^{*}$ & 1 & $-1.043(1)$ & 4 \\
& $0.407^{*}$ & 1 & $0.255(0)$ & 5 \\
$\ln \mathrm{GDP}$ & $0.406^{*}$ & 1 & $0.450(0)$ & 5 \\
$\ln \mathrm{GDP}{ }^{2}$ & $0.347^{*}$ & 1 & $-1.807(1)$ & 3 \\
$\ln \mathrm{FDI}$ & $0.410^{*}$ & 1 & $-2.064(9)$ & 5 \\
$\ln \mathrm{EC}$ & & 1 &
\end{tabular}

Notes: * denotes the rejection of the null hypothesis at the $1 \%$ significance levels. Numbers in the parantheses show the optimal lag lengths are determined through Akaike Info Criterion (AIC). $k^{*}$ is the optimal frequency.

The results of FKPSS stationarity test indicate that the null hypothesis of stationarity is rejected for all the series. These results are also confirmed by the FF-ADF unit root test. We cannot reject the unit root null hypothesis for all analyzed series. As a final result, all the variables follow unit root process based on both tests.

After the unit root tests, the second stage requires testing for the existence of a long-run equilibrium relationship among variables. For this purpose, Fourier ADL and Fourier Shin cointegration tests are applied and results are reported in Table 4.

Table 4: The Results of Fourier Cointegration Tests

\begin{tabular}{ccc}
\hline Cointegration Test & Test Statistics & $k^{*}$ \\
\hline \hline$t_{A D L}^{F}$ & $-6.193(0)^{*}$ & 4 \\
$C I_{f}^{m}$ & 0.072 & 3 \\
\hline \hline
\end{tabular}

Notes: Critical values for FADL, and FSHIN cointegration tests at the $1 \%$ levels are -5.024, and 0192, respectively.

$*$ denotes the rejection of the null hypothesis no cointegration at the $1 \%$ significance level. The optimal lag length is determined through Akaike Information Criterion (AIC). $k^{*}$ displays the optimal frequency.

The result of the Fourier ADL based on the test statistic denoted by $t_{A D L}^{F}\left(k^{*}\right)$ show that 
level. When we allow for an unknown number of smooth structural shifts in cointegration relationship, the results imply the stochastic comovement between $\mathrm{CO}_{2}$ emissions and independent variables which are GDP, GDP ${ }^{2}$, FDI, EC for Turkey. Since Banerjee et al. (2017) generated critical values for three independent variables, we are forced to compute critical values for four independent variables in a similar manner, based on Monte Carlo simulations. Computed critical values is Appendix A. The test results of the Fourier ADL cointegration reject the null hypothesis no cointegration at $1 \%$ significance level. The results of the Fourier Shin cointegration test also confirmed the presence of a long-run equilibrium relationship between $\mathrm{CO}_{2}$ emissions and its determinants. Thus, we conclude that there is strong evidence of a long-run relationship among the variables.

Since there exists the cointegration relationship, the long-run relationships among the variables could be estimated by the fully modified OLS (FMOLS) approach suggested by Phillips and Hansen (1990). The FMOLS estimator generates consistent estimates in small samples, is also highly efficient in handling the issue of the endogeneity among variables, and serial correlations in the error terms. The result of the FMOLS associated with Eq.(2) is illustrated in Table 5.

Table 5: The Estimated Long-Run Coefficients Fourier

\begin{tabular}{lcc}
\hline \multicolumn{1}{c}{ Variable } & Coefficient & t-Statistic \\
\hline $\ln$ GDP & 3.998 & $2.666^{* *}$ \\
$\ln$ GDP & -0.207 & $-2.644^{* *}$ \\
$\ln$ FDI & 0.006 & $1.974 * * *$ \\
$\ln$ EC & 0.642 & $7.061^{*}$ \\
Constant & -20.686 & $-3.005^{*}$ \\
SSIN & 0.014 & $3.138^{*}$ \\
CCOS & -0.013 & $-2.802^{*}$ \\
\hline Notes: ***, and *** denote the statistically significance of the coefficients at the $1 \%, 5 \%$, and $10 \%$ levels, respectively.
\end{tabular}

465

As can be seen from Table 5, all the coefficients in the model have the expected sign are found as statistically significant at traditional significance levels. The coefficient of GDP per capita is positive, while the coefficient of GDP per capita sqared is negative. This means that per capita $\mathrm{CO}_{2}$ emissions in other words environmental pollution increases at the initial phase of economic growth, but then per capita $\mathrm{CO}_{2}$ emissions starts to decline after reaching a certain level of economic growth. Given this findings, we can conclude that the conventional EKC hypothesis is valid for Turkey. This result is in line with the findings of by Halicioglu (2009), Pata (2018), Yavuz Cil (2014), Kirikkaleli and Kalmaz (2020). The outcomes are demonstrate that when holding the other variables fixed, $1 \%$ increase in the GDP per capita will 
lead to a $3.998 \%$ increase at $\mathrm{CO}_{2}$ per capita emissions. In addition to, the marginal effect of

477 GDP per capita on $\mathrm{CO}_{2}$ per capita emissions is calculated by $478 \partial \ln C_{2} / \partial \ln G D P=3.998-0.414 \times G D P$ and turning point of Environmental Kuznets Curve is 9.657 (= 3.998/0.414, in logarithms) in Turkey. The monetary value of the turning point is equal to 15630.8 US dolars. However, it is outside of the sample period. Similarly, Pata (2018), Bölük and Mert (2015) and Tutulmaz (2015), which found the turning point for Turkey to be outside of the sample period. When EKC hypothesis is valid but calculated turning point in per capita dollars is outside the sample, Holtz-Eakin and Selden (1995) concluded that a country's marginal propensity to emit trends towards zero as incomes rise, rather than becoming negative. Foreign direct investment has positive impact on $\mathrm{CO}_{2}$ emissions, results in the Table 5 provides evidence in the favor of the PPH as the coefficient of the per capita real foreign direct investment variable is significant at $10 \%$. Also, the long-term elasticity of FDI inflow is equal to 0.006 which is very low. This implies that $\mathrm{CO}_{2}$ emissions will increase by $0.006 \%$ for every $1 \%$ increase in foreign direct investment inflow. Thus we can say that the effect of FDI inflow on the environmental degration is very weak during the estimation period. This result is consistent with the findings of Halicioglu (2009) and Seker et al. (2015) in case Turkey. Agras and Chapman (1999) stated low income developing countries either unable to attract the FDI or only attracts the FDI in the service sector, which cast a lower impact on carbon emission. When the sectoral distribution of foreign direct investments in Turkey, which is a developing country, is analyzed, it is observed that foreign direct investments made especially in finance and insurance activities and information and communication sub-sectors have increased since 2005, and as of the end of 2016, electricity, gas, steam and air conditioning production and distribution, as well as wholesale and retail trade sectors have come to the fore in the sectoral distribution in addition to these sectors.

According to results in Table 5, coefficient of energy consumption is highly significant and energy consumption has positive effect on the $\mathrm{CO}_{2}$. The elasticity coefficient between the energy consumption and the $\mathrm{CO}_{2}$ emissions is 0.642 , implying that $1 \%$ increase in per capita energy consumption will lead to increase $0.642 \%$ at per capita $\mathrm{CO}_{2}$ emissions in the long run. Thus, energy consumption will increase environmental degradation in long -run. The finding is in line with those found by Ozturk and Acaravci (2010), Yavuz Cil (2014), Katircioglu (2014), Destek and Ozsoy (2015).

The presence of cointegration provides information only about the long-run relationship among the variables and indicates that there is at least one long-run relationship relationship 
509 (Engle and Granger, 1987). However, evidence of cointegration that implies the existence of 510 causality at least in one direction does not indicate the direction of the causal relationship. 511 Therefore, in final step of empirical investigation of this study, we investigate the direction of 512 causalty relationship between $\mathrm{CO}_{2}$ emissions, GDP, FDI and EC with using the Fourier TY 513 causality test, due to the advantages as mentioned above. We report the results of Fourier TY 514 causality test in Table 6.

$516 \quad$ Table 6: Fourier TY causality test results

\begin{tabular}{|c|c|c|c|c|}
\hline Direction & Wald Test Stat. & Bootstrap $p$-Value & Lag Length & Optimal Frequency \\
\hline $\ln \mathrm{CO}_{2} \rightarrow \ln \mathrm{GDP}$ & 0.611 & 0.4403 & 1 & 0.1 \\
\hline $\ln \mathrm{FDI} \rightarrow \ln \mathrm{GDP}$ & 0.655 & 0.4128 & 1 & 0.1 \\
\hline $\ln \mathrm{EC} \rightarrow \ln \mathrm{GDP}$ & 0.002 & 0.9648 & 1 & 0.1 \\
\hline $\ln \mathrm{GDP}^{2} \rightarrow \ln \mathrm{GDP}$ & 0.044 & 0.8397 & 1 & 0.1 \\
\hline $\ln \mathrm{GDP} \rightarrow \ln \mathrm{CO}_{2}$ & $3.691 *$ & 0.0623 & 1 & 0.1 \\
\hline $\ln \mathrm{FDI} \rightarrow \ln \mathrm{CO}_{2}$ & 1.020 & 0.3171 & 1 & 0.1 \\
\hline $\ln \mathrm{EC} \rightarrow \ln \mathrm{CO}_{2}$ & 0.008 & 0.9286 & 1 & 0.1 \\
\hline $\ln \mathrm{GDP}^{2} \rightarrow \ln \mathrm{CO}_{2}$ & $3.622 *$ & 0.0676 & 1 & 0.1 \\
\hline $\ln \mathrm{GDP} \rightarrow \ln \mathrm{FDI}$ & 2.108 & 0.153 & 1 & 0.1 \\
\hline $\ln \mathrm{CO}_{2} \rightarrow \ln \mathrm{FDI}$ & 0.183 & 0.6691 & 1 & 0.1 \\
\hline $\ln \mathrm{EC} \rightarrow \ln \mathrm{FDI}$ & 0.004 & 0.9473 & 1 & 0.1 \\
\hline $\ln \mathrm{GDP}^{2} \rightarrow \ln \mathrm{FDI}$ & 2.181 & 0.1505 & 1 & 0.1 \\
\hline $\ln \mathrm{GDP} \rightarrow \ln \mathrm{EC}$ & $3.183^{*}$ & 0.0866 & 1 & 0.1 \\
\hline $\ln \mathrm{CO}_{2} \rightarrow \ln \mathrm{EC}$ & 2.171 & 0.1469 & 1 & 0.1 \\
\hline $\ln \mathrm{FDI} \rightarrow \ln \mathrm{EC}$ & 1.077 & 0.2984 & 1 & 0.1 \\
\hline $\ln \mathrm{GDP}^{2} \rightarrow \ln \mathrm{EC}$ & $3.080^{*}$ & 0.0883 & 1 & 0.1 \\
\hline $\ln \mathrm{GDP} \rightarrow \ln \mathrm{GDP}^{2}$ & 0.022 & 0.8803 & 1 & 0.1 \\
\hline $\ln \mathrm{CO}_{2} \rightarrow \ln \mathrm{GDP}^{2}$ & 0.521 & 0.4703 & 1 & 0.1 \\
\hline $\ln \mathrm{FDI} \rightarrow \ln \mathrm{GDP}^{2}$ & 0.687 & 0.4128 & 1 & 0.1 \\
\hline $\ln \mathrm{EC} \rightarrow \ln \mathrm{GDP}^{2}$ & 0.000 & 0.9998 & 1 & 0.1 \\
\hline
\end{tabular}

Note: $*$ Significant at $10 \%$ level. Number of bootstrap replications: 10000 . The optimal lag lengths is determined through Schwarz Info Criterion (SIC).

The results in Table 6 show that there is a uni-directional causality exists from the GDP to the $\mathrm{CO}_{2}$ and $\mathrm{EC}$, and also from $\mathrm{GDP}^{2}$ to $\mathrm{CO}_{2}$ and $\mathrm{EC}$, it implies that a higher economic growth increases both $\mathrm{CO}_{2}$ emissions and the energy consumption. This result is possible consequence for Turkey as developing country that use coal and high carbon energy in production.

The causality result also confirms the valid of Kuznets Curve hypothesis. These findings also support the results of the cointegration test. Economic growth and and energy consumption are the main determinants of $\mathrm{CO}_{2}$ emissions and any change in one or both of these variables 
will affect of pollution in Turkey. While it has been determined that there is a long-term relationship between foreign direct investment inflows and $\mathrm{CO}_{2}$ emissions in the sampling period in Turkey, there is no causal relationship between them.

\section{Conclusion}

As there is an ongoing debate on the role of greenhouse gas emissions in global warning and climate change, it has become important to identify and measure the impact of potential factors in increasing greenhouse gas emissions. One of these potential factors discussed in academic and scientific circles is foreign direct investment inflows. In theory, although FDI inflows have the potential to positively affect host country's development process, there is empirical evidence in recently energy economics literature about FDI inflows can contribute to environmental degradation by increasing greenhouse gas emissions. The effect of FDI inflows increasing the environmental degradation of the host country is called $\mathrm{PHH}$.

The main focus of the current study is to examine the effect of the FDI inflows on environmental degradation. Hence, it is considered whether or not the $\mathrm{PHH}$ is confirmed for Turkey over the period 1970-2016, within an EKC hypothesis framework. In doing so, Fourier approximation is preferred to determine the stationarity properties of the variables and to analyze the relationship between them, unlike other studies. Thus, the new evidences are provided in our study.

Empirical findings suggest some important results. (i) Foreign direct investment has positive impact on $\mathrm{CO}_{2}$ emissions, which implies the validity the $\mathrm{PHH}$ for Turkey. (ii) Economic growth and square of GDP exhibit positive and negative effect on $\mathrm{CO} 2$ emissions respectively, implying the validity of EKC hypothesis. Economic growth is an important determinant of the environmental degradation. (iii) Energy consumption has positive impact on $\mathrm{CO} 2$ emissions. Energy consumption, like economic growth, is also an important factor for environmental degradation. The enhancing effect of economic growth and energy consumption on environmental degradation is consistent with the experience of many developing countries. (iv) Granger causality results show that there is a uni-directional causality exists from the economic growth to the $\mathrm{CO}_{2}$ emissions and energy consumption.

Depending on the findings, we suggest that government should policy to encourage foreign direct investment that is used environmental friendly and novel technologies. As the Turkish economy is a growing economy, environmental problems in general will become even more pronounced by increases in energy use. Energy policies implemented should be energy 
562 intensity reducer and efficiency increase, in order to keep the rising trend of $\mathrm{CO}_{2}$ emissions

563 under control arising from increasing energy demand owing to economic growth. Over time, to 564 reduce the use of polluting energy sources such as coal and oil and to increase renewable energy 565 investments that are solar, wind, geothermal and hydropower could be a powerful way for 566 improving environmental quality, especially in Turkey and other developing countries.

567 In the context of PHH and PHL, it would be useful to analyze the environmental impacts 568 of FDI by extending for different sectors in further studies for the case of Turkey, due to sectoral 569 differences.

$570 \quad$ Appendix A

\begin{tabular}{cccc}
\hline$T=100$ & & & \\
\hline$k=4$ & $\mathbf{1 \%}$ & $\mathbf{5 \%}$ & $\mathbf{1 0 \%}$ \\
& & & \\
\hline 1 & $\mathbf{- 5 . 3 7 8}$ & -4.691 & -4.338 \\
2 & -5.271 & -4.579 & -4.205 \\
3 & -5.147 & -4.428 & -4.042 \\
4 & $\mathbf{- 5 . 0 2 4}$ & $\mathbf{- 4 . 2 9 8}$ & $\mathbf{- 3 . 9 0 8}$ \\
5 & -4.923 & -4.202 & -3.824 \\
\hline
\end{tabular}

571

572 Ethical Approval Not applicable

573 Consent to Participate Not applicable

574 Consent to Publish Not applicable

575 Authors Contributions Original draft preparation, conceptualization, methodology, 576 modelling, data collection, and analysis etc. all the processes were performed by the author.

577 Funding No funds were received.

578 Competing Interests The authors declare no competing interests.

579 Availability of data and materials All data analysed during this study are included in this 580 published article.

\section{References}

583 Acharyya, J. (2009). Fdi, Growth and the Environment: Evidence From India on CO2 Emission 584 During the Last Two Decades. Journal of Economic Development, 34(1), 43-58. 585 https://doi.org/10.35866/caujed.2009.34.1.003

586 Agras, J., \& Chapman, D. (1999). A dynamic approach to the Environmental Kuznets Curve 587 hypothesis. Ecological Economics, 28(2), 267-277. https://doi.org/10.1016/S0921588 8009(98)00040-8

589 Al-mulali, U. (2012). Factors affecting CO2 emission in the Middle East: A panel data analysis. 590 Energy, 44(1), 564-569. https://doi.org/10.1016/J.ENERGY.2012.05.045

591 Al-mulali, U., \& Foon Tang, C. (2013). Investigating the validity of pollution haven hypothesis 
in the gulf cooperation council (GCC) countries. Energy Policy, 60, 813-819.

593 https://doi.org/10.1016/J.ENPOL.2013.05.055

594 Al-Mulali, U., \& Ozturk, I. (2015). The effect of energy consumption, urbanization, trade openness, industrial output, and the political stability on the environmental degradation in the MENA (Middle East and North African) region. Energy, 84, 382-389. https://doi.org/10.1016/j.energy.2015.03.004

598

599

600

601

602

603

604

605

606

607

608

609

610

611

612

613

614

615

616

617

618

619

620

621

622

623

624

625

626

627

628

629

630

631

632

633

634

635

Ang, J. B. (2007). CO2 emissions, energy consumption, and output in France. Energy Policy, 35(10), 4772-4778. https://doi.org/10.1016/j.enpol.2007.03.032

Apergis, N., \& Payne, J. E. (2009). CO2 emissions, energy usage, and output in Central America. Energy Policy, 37(8), 3282-3286. https://doi.org/10.1016/j.enpol.2009.03.048

Arouri, M. E. H., Ben Youssef, A., M'henni, H., \& Rault, C. (2012). Energy consumption, economic growth and $\mathrm{CO} 2$ emissions in Middle East and North African countries. Energy Policy, 45, 342-349. https://doi.org/10.1016/j.enpol.2012.02.042

Atici, C. (2012). Carbon emissions, trade liberalization, and the Japan-ASEAN interaction: A group-wise examination. Journal of the Japanese and International Economies, 26(1), 167178. https://doi.org/10.1016/J.JJIE.2011.07.006

Banerjee, P., Arčabić, V., \& Lee, H. (2017). Fourier ADL cointegration test to approximate smooth breaks with new evidence from Crude Oil Market. Economic Modelling, 67, 114-124. https://doi.org/10.1016/j.econmod.2016.11.004

Becker, R., Enders, W., \& Hurn, S. (2004). A general test for time dependence in parameters. Journal of Applied Econometrics, 19(7), 899-906. https://doi.org/10.1002/jae.751

Becker, R., Enders, W., \& Lee, J. (2006). A stationarity test in the presence of an unknown number of smooth breaks. Journal of Time Series Analysis, 27(3), 381-409. https://doi.org/10.1111/j.1467-9892.2006.00478.x

Bölük, G., \& Mert, M. (2015). The renewable energy, growth and environmental Kuznets curve in Turkey: An ARDL approach. In Renewable and Sustainable Energy Reviews (Vol. 52, pp. 587-595). Elsevier Ltd. https://doi.org/10.1016/j.rser.2015.07.138

Bulut, U., Ucler, G., \& Inglesi-Lotz, R. (2021). Does the pollution haven hypothesis prevail in Turkey? Empirical evidence from nonlinear smooth transition models. Environmental Science and Pollution Research, 28, 38563-38572. https://doi.org/10.1007/s11356-021-13476-7

Charfeddine, L. (2017). The impact of energy consumption and economic development on Ecological Footprint and CO2 emissions: Evidence from a Markov Switching Equilibrium Correction $\quad$ Model. Energy 355-374. https://doi.org/10.1016/j.eneco.2017.05.009

Cole, M. A. (2004). Trade, the pollution haven hypothesis and the environmental Kuznets curve: Examining the linkages. Ecological Economics, 48(1), 71-81. https://doi.org/10.1016/j.ecolecon.2003.09.007

Cole, M. A., \& Elliott, R. J. R. (2005). FDI and the Capital Intensity of "Dirty" Sectors: A Missing Piece of the Pollution Haven Puzzle. Review of Development Economics, 9(4), 530548. https://doi.org/10.1111/j.1467-9361.2005.00292.x

Day, K. M., \& Grafton, R. Q. (2003). Growth and the Environment in Canada: An Empirical Analysis. Canadian Journal of Agricultural Economics, 51, 197-216. https://doi.org/10.1111/j.1744-7976.2003.tb00173.x

De Camargo Fiorini, P., Jabbou, C. J. C., Jabbour, A. B. L. de S., Stefanelli, N. O., \& Fernando, 
Y. (2019). Interplay between information systems and environmental management in ISO 14001-certified companies: Implications for future research on big data. Management Decision, 57(8), 1883-1901. https://doi.org/10.1108/MD-07-2018-0739

Destek, M. A., \& Ozsoy, F. N. (2015). Relationships between economic growth, energy consumption, globalization, urbanization and environmental degradation in Turkey. 641 International Journal of Energy and Statistics, 03(04), 1550017. 642 https://doi.org/10.1142/S2335680415500179

643 Dinda, S. (2004). Environmental Kuznets Curve hypothesis: A survey. Ecological Economics, 644 49(4), 431-455. https://doi.org/10.1016/j.ecolecon.2004.02.011 Enders, W., \& Jones, P. (2016). Grain prices, oil prices, and multiple smooth breaks in a VAR. 646 Studies in Nonlinear Dynamics and Econometrics, 20(4), 399-419. https://doi.org/10.1515/snde-2014-0101

648 Enders, W., \& Lee, J. (2012a). A unit root test using a fourier series to approximate smooth 649 breaks. Oxford Bulletin of Economics and Statistics, 74(4), 574-599. 650 https://doi.org/10.1111/j.1468-0084.2011.00662.x

651 Enders, W., \& Lee, J. (2012b). The flexible Fourier form and Dickey-Fuller type unit root tests. 652 Economics Letters, 117(1), 196-199. https://doi.org/10.1016/j.econlet.2012.04.081

653 Engle, R. F., \& Granger, C. W. J. (1987). Co-Integration and Error Correction: Representation, 654 Estimation, and Testing. Econometrica, 55(2), 251-276. https://doi.org/10.2307/1913236

655 Furuoka, F. (2015). The CO2 emissions-development nexus revisited. Renewable and Sustainable Energy Reviews, 51, 1256-1275. https://doi.org/10.1016/j.rser.2015.07.049

657

658

659

660

661

662

663

664

665

666

667

668

669

670

671

672

673

674

675

676

677

678

679

Gökmenoğlu, K., \& Taspinar, N. (2016). The relationship between CO2 emissions, energy consumption, economic growth and FDI: the case of Turkey. Journal of International Trade and Economic Development, 25(5), 706-723. https://doi.org/10.1080/09638199.2015.1119876

Gray, K. R. (2002). Foreign direct investment and environmental impacts - Is the debate over? Review of European Community and International Environmental Law, 11(3), 306-313. https://doi.org/10.1111/1467-9388.00329

Grossman, G., \& Krueger, A. (1991). Environmental Impacts of a North American Free Trade Agreement. National Bureau of Economic Research, Article 3914. https://doi.org/10.3386/w3914

Grossman, G. M., \& Krueger, A. B. (1995). Economic Growth and the Environment. Source: The Quarterly Journal of Economics, 110(2), 353-377. https://doi.org/10.2307/2118443

Halicioglu, F. (2009). An econometric study of $\mathrm{CO} 2$ emissions, energy consumption, income and foreign trade in Turkey. Energy Policy, 37(3), 1156-1164. https://doi.org/10.1016/j.enpol.2008.11.012

Haug, A. A., \& Ucal, M. (2019). The role of trade and FDI for CO2 emissions in Turkey: Nonlinear relationships. Energy Economics, 81, 297-307. https://doi.org/10.1016/j.eneco.2019.04.006

Holtz-Eakin, D., \& Selden, T. M. (1995). Stoking the fires? CO2 emissions and economic growth. Journal of Public Economics, 57(1), 85-101. https://doi.org/10.1016/00472727(94)01449-X

Katircioglu, S. T. (2014). International tourism, energy consumption, and environmental pollution: The case of Turkey. In Renewable and Sustainable Energy Reviews (Vol. 36, pp. 180-187). Elsevier Ltd. https://doi.org/10.1016/j.rser.2014.04.058 
Kearsley, A., \& Riddel, M. (2010). A further inquiry into the Pollution Haven Hypothesis and the Environmental Kuznets Curve. Ecological Economics, 69(4), 905-919. https://doi.org/10.1016/j.ecolecon.2009.11.014

683

684

685

686

687

688

689

690

691

692

693

694

695

696

697

698

699

700

701

702

703

704

705

706

707

708

709

710

711

712

713

714

715

716

717

718

Kirikkaleli, D., \& Kalmaz, D. B. (2020). Testing the moderating role of urbanization on the environmental Kuznets curve: empirical evidence from an emerging market. Environmental Science and Pollution Research, 27(30), 38169-38180. https://doi.org/10.1007/s11356-02009870-2

Kirkulak, B., Qiu, B., \& Yin, W. (2011). The impact of FDI on air quality: Evidence from China. Journal of Chinese Economic and Foreign Trade Studies, 4(2), 81-98. https://doi.org/10.1108/17544401111143436

Koçak, E., \& Şarkgüneşi, A. (2018). The impact of foreign direct investment on CO2 emissions in Turkey: new evidence from cointegration and bootstrap causality analysis. Environmental Science and Pollution Research, 25(1), 790-804. https://doi.org/10.1007/s11356-017-0468-2

Kwiatkowski, D., Phillips, P. C. B., Schmidt, P., \& Shin, Y. (1992). How sure are we that economic time series have a unit root? Journal of Econometrics, 54, 159-178. https://doi.org/10.1016/0304-4076(92)90104-Y

Lee, J. W. (2013). The contribution of foreign direct investment to clean energy use, carbon emissions and economic growth. Energy Policy, 55, 483-489. https://doi.org/10.1016/j.enpol.2012.12.039

Merican, Y., Yusop, Z., Noor, Z. M., \& Law, S. H. (2007). Foreign Direct Investment and the Pollution in Five ASEAN Nations. Journal of Economics and Management, 1(2), 245-261.

Nazlioglu, S., Gormus, N. A., \& Soytas, U. (2016). Oil prices and real estate investment trusts (REITs): Gradual-shift causality and volatility transmission analysis. Energy Economics, 60, 168-175. https://doi.org/10.1016/j.eneco.2016.09.009

Omri, A., Nguyen, D. K., \& Rault, C. (2014). Causal interactions between CO2 emissions, FDI, and economic growth: Evidence from dynamic simultaneous-equation models. Economic Modelling, 42, 382-389. https://doi.org/10.1016/j.econmod.2014.07.026

Opoku, E. E. O., Adams, S., \& Aluko, O. A. (2021). The foreign direct investment-environment nexus: Does emission disaggregation matter? Energy Reports, 7, 778-787. https://doi.org/10.1016/j.egyr.2021.01.035

Ozturk, I., \& Acaravci, A. (2010). CO2 emissions, energy consumption and economic growth in Turkey. In Renewable and Sustainable Energy Reviews (Vol. 14, Issue 9). Elsevier Ltd. https://doi.org/10.1016/j.rser.2010.07.005

Panayotou, T. (1993). Empirical tests and policy analysis of environmental degradation at different stages of economic development. In Pacific and Asian Journal of Energy (Vol. 4, Issue 1). International Labour Office.

Pao, H. T., \& Tsai, C. M. (2010). CO2 emissions, energy consumption and economic growth in BRIC countries. Energy Policy, 38(12), 7850-7860. https://doi.org/10.1016/j.enpol.2010.08.045

Pao, H. T., \& Tsai, C. M. (2011a). Multivariate Granger causality between CO2 emissions, energy consumption, FDI (foreign direct investment) and GDP (gross domestic product): Evidence from a panel of BRIC (Brazil, Russian Federation, India, and China) countries. Energy, 36(1), 685-693. https://doi.org/10.1016/J.ENERGY.2010.09.041

Pao, H. T., \& Tsai, C. M. (2011b). Modeling and forecasting the CO2 emissions, energy 
consumption, and economic growth in

Brazil. Energy, 36(5),

725 https://doi.org/10.1016/J.ENERGY.2011.01.032

Pata, U. K. (2018). The influence of coal and noncarbohydrate energy consumption on $\mathrm{CO} 2$ emissions: Revisiting the environmental Kuznets curve hypothesis for Turkey. Energy, 160, 1115-1123. https://doi.org/10.1016/j.energy.2018.07.095

Perkins, R., \& Neumayer, E. (2009). Transnational linkages and the spillover of environmentefficiency into developing countries. Global Environmental Change, 19(3), 375-383. https://doi.org/10.1016/j.gloenvcha.2009.05.003

Perron, P. (1989). The Great Crash, the Oil Price Shock, and the Unit Root Hypothesis. Econometrica, 57(6), 1361. https://doi.org/10.2307/1913712

Phillips, P. C. B., \& Hansen, B. E. (1990). Statistical inference in instrumental variables regression with $\mathrm{i}(1)$ processes. Review of Economic Studies, 57(1), 99-125. https://doi.org/10.2307/2297545

Roca, J., Padilla, E., Farré, M., \& Galletto, V. (2001). Economic growth and atmospheric pollution in Spain: discussing the environmental Kuznets curve hypothesis. In Ecological Economics (Vol. 39). www.elsevier.com/locate/ecolecon

Rodrigues, P. M. M., \& Robert Taylor, A. M. (2012). The flexible fourier form and local generalised least squares de-trended unit root tests. Oxford Bulletin of Economics and Statistics, 74(5), 736-759. https://doi.org/10.1111/j.1468-0084.2011.00665.x

Seker, F., Ertugrul, H. M., \& Cetin, M. (2015). The impact of foreign direct investment on environmental quality: A bounds testing and causality analysis for Turkey. In Renewable and Sustainable Energy Reviews (Vol. 52, pp. 347-356). Elsevier Ltd. https://doi.org/10.1016/j.rser.2015.07.118

Shafik, N. (1994). Economic Development and Environmental Quality: An Econometric Analysis. In Source: Oxford Economic Papers (Vol. 46). https://about.jstor.org/terms

Shahbaz, M., Khraief, N., Uddin, G. S., \& Ozturk, I. (2014). Environmental Kuznets curve in an open economy: A bounds testing and causality analysis for Tunisia. In Renewable and Sustainable Energy Reviews (Vol. 34, pp. 325-336). Elsevier Ltd. https://doi.org/10.1016/j.rser.2014.03.022

Shahbaz, M., Nasir, M. A., \& Roubaud, D. (2018). Environmental degradation in France: The effects of FDI, financial development, and energy innovations. Energy Economics, 74, 843857. https://doi.org/10.1016/j.eneco.2018.07.020

Shahbaz, M., Nasreen, S., Abbas, F., \& Anis, O. (2015). Does foreign direct investment impede environmental quality in high-, middle-, and low-income countries? Energy Economics, 51, 275-287. https://doi.org/10.1016/j.eneco.2015.06.014

Shahbaz, M., Zeshan, M., \& Afza, T. (2012). Is energy consumption effective to spur economic growth in Pakistan? New evidence from bounds test to level relationships and Granger causality tests. Economic Modelling, 29(6), 2310-2319. https://doi.org/10.1016/j.econmod.2012.06.027

Soytas, U., \& Sari, R. (2003). Energy consumption and GDP: Causality relationship in G-7 countries and emerging markets. Energy Economics, 25(1), 33-37. https://doi.org/10.1016/S0140-9883(02)00009-9

Soytas, U., Sari, R., \& Ewing, B. T. (2007). Energy consumption, income, and carbon emissions in the United States. Ecological Economics, 62(3-4), 482-489. https://doi.org/10.1016/j.ecolecon.2006.07.009 
Sun, C., Zhang, F., \& Xu, M. (2017). Investigation of pollution haven hypothesis for China: An ARDL approach with breakpoint unit root tests. Journal of Cleaner Production, 161, 153-164. https://doi.org/10.1016/j.jclepro.2017.05.119

Talukdar, D., \& Meisner, C. M. (2001). Does the private sector help or hurt the environment? Evidence from carbon dioxide pollution in developing countries. World Development, 29(5), 827-840. https://doi.org/10.1016/S0305-750X(01)00008-0

774

775

776

777

778

779

780

781

782

783

784

785

786

787

788

789

790

791

792

793

794

795

796

797

798

799

800

801

802

803

804

805

806

807

808

809

810

Tang, C. F., \& Tan, B. W. (2015). The impact of energy consumption, income and foreign direct investment on carbon dioxide emissions in Vietnam. Energy, 79, 447-454. https://doi.org/10.1016/j.energy.2014.11.033

Taylor, M. S. (2005). Unbundling the Pollution Haven Hypothesis. Advances in Economic Analysis \& Policy, 3(2). https://doi.org/10.2202/1538-0637.1408

Toda, H. Y., \& Yamamoto, T. (1995). Statistical inference in vector autoregressions with possibly integrated processes. Journal of Econometrics, 66(1-2), 225-250. https://doi.org/10.1016/0304-4076(94)01616-8

Tsong, C. C., Lee, C. F., Tsai, L. J., \& Hu, T. C. (2016). The Fourier approximation and testing for the null of cointegration. Empirical Economics, 51(3), 1085-1113. https://doi.org/10.1007/s00181-015-1028-6

Tutulmaz, O. (2015). Environmental Kuznets Curve time series application for Turkey: Why controversial results exist for similar models? In Renewable and Sustainable Energy Reviews (Vol. 50, pp. 73-81). Elsevier Ltd. https://doi.org/10.1016/j.rser.2015.04.184

Ventosa-Santaulària, D., \& Vera-Valdés, J. E. (2008). Granger-Causality in the presence of structural breaks. Economics Bulletin, http://www.accessecon.com/pubs/EB/2008/Volume3/EB-08C20013A.

Walter, I., \& Ugelow, J. L. (1979). Environmental Policies in Developing Countries. In Technology, Development and Environmental Impact (Vol. 8, Issue 3).

Wang, Q., Zhao, M., Li, R., \& Su, M. (2018). Decomposition and decoupling analysis of carbon emissions from economic growth: A comparative study of China and the United States. Journal of Cleaner Production, 197, 178-184. https://doi.org/10.1016/j.jclepro.2018.05.285

Wang, Y., Zhang, C., Lu, A., Li, L., He, Y., ToJo, J., \& Zhu, X. (2017). A disaggregated analysis of the environmental Kuznets curve for industrial $\mathrm{CO} 2$ emissions in China. Applied Energy, 190, 172-180. https://doi.org/10.1016/j.apenergy.2016.12.109

Yavuz Cil, N. (2014). CO2 Emission, energy consumption, and economic growth for Turkey: Evidence from a cointegration test with a structural break. Energy Sources, Part B: Economics, Planning and Policy, 9(3), 229-235. https://doi.org/10.1080/15567249.2011.567222

Zarsky, L. (1999). Havens, Halos and Spaghetti: Untangling the Evidence about Foreign Direct Investment and the Environment. In Foreign Direct Investment and the Environment (pp. 4774). OECD Publications Servise.

Zhang, C., \& Zhou, X. (2016). Does foreign direct investment lead to lower CO2 emissions? Evidence from a regional analysis in China. Renewable and Sustainable Energy Reviews, 58, 943-951. https://doi.org/10.1016/j.rser.2015.12.226

TUIK

Global Carbon Atlas 